\title{
Genetic Research Progress of Fruit Ripening and Quality Control
}

$\mathrm{Xu}$ Zhuye ${ }^{1}$, Tang Fenling ${ }^{2}$, Wang Anbang ${ }^{2}$, Li Yujia ${ }^{2}$, Xu Yi ${ }^{2}$, Lin Fei ${ }^{2}$, Wei Qing ${ }^{2}$, Wang Jiashui ${ }^{2}$, Gong Deyong ${ }^{3}$, Li Jingyang ${ }^{1,2} \not$

1 College of Horticultural,Hainan University, Haikou, 571101

2 Hainan Banana Healthy Seedling Propagation Engineering Research Center, Haikou Experimental Station, Chinese Academy of Tropical Agricultural Sciences, Haikou, 571101

3 Institute of subtropical crops, Guizhou Academy of Agricultural Sciences, Xinyi, 562400

$\square$ Corresponding author Email: jingyanglee@163.com

Molecular Plant Breeding, 2019, Vol.10, No.13 doi: 10.5376/mpb.2019.10.0014

Received: 14 Aug., 2019

Accepted: 12 Sep., 2019

Published: 18 Sep., 2019

Copyright $\odot 2019$ Xu et al., This article was first published in Molecular Plant Breeding (2018, 16(4): 1320-1326) in Chinese, and here was authorized to translate and publish the paper in English under the terms of Creative Commons Attribution License, which permits unrestricted use, distribution, and reproduction in any medium, provided the original work is properly cited.

Preferred citation for this article:

Xu Z.Y., Tang F.L., Wang A.B., Li Y.J., Xu Y., Lin F., Wei Q., Wang J.S., Gong D.Y., and Li J.Y., 2019, Genetic research progress of fruit ripening and quality control, Molecular Plant Breeding, 10(14): 108-115 (doi: 10.5376/mpb.2019.10.0014)

\begin{abstract}
Fruit ripening involves many biochemical processes, mainly including aroma, sugar production, fruit softening and so on, which is closely related to a series of metabolic pathways in the process of fruit ripening. Therefore, it is of great significance for fruit quality improvement to study and understand the genetic mechanism of fruit ripening and quality regulation. Combined with the genetic studies of fruit ripening and quality improvement in recent years, this study summarized metabolic pathways in genetic analysis of fruit ripening, genetic law of fruit quality improvement, and quality QTL, aiming to provide technical reference for quality breeding of fruit plants.
\end{abstract}

Keywords Alternative oxidase, Uncoupling protein, Polyamines, Transcription factors, Quantitative trait locus

The breeding of high-quality varieties is very important for the sustainable development of fruit industry. Fruit quality is a comprehensive trait composed of many single traits, many of which are quantitative traits or quantitative-qualitative traits controlled by micro functional polygenes or oligo genes (Chen et al., 2015). According to the purpose of research and utilization, the fruit quality can be divided into appearance, flavor, nutrition, storage and transportation, fresh food, processing, heredity and other different types of quality. The components include size, shape, color, texture, flavor, aroma and functional components of the fruit (Duangit et al., 2016). Since ancient times, the regulation of fruit development, maturation and quality formation has been a hot issue for fruit breeders.

\section{Fruit Ripening Regulation}

\subsection{Regulation of AOX and UCP metabolic pathways in fruit ripening}

In the process of climacteric fruit ripening, ethylene played a role in inducing and promoting ripening of these fruits. When the fruit was ripe, it would change in nutrients, texture and color. The accumulation of sugar and the increase of respiratory activity were attributed to the effect of ethylene and the response to environmental disturbance under the regulation of genes (Vanlerberghe et al., 2013). The increase of respiratory activity during respiration climacteric fruit ripening was related to ATP synthesis and uncoupling between mitochondrial electron transport chains. The two energy consumption systems involved, one of which was mediated by alternating oxidase (AOX) and the other by uncoupling protein (UCP), were both related to fruit maturation (Seymour et al., 2013). To illustrate this problem, Oliveira et al. (2015) monitored ethylene emissions and two uncoupling (AOX and UCP) pathways during maturation of papaya (from green to yellow). The results showed that papaya was a typical respiration climacteric fruit: endogenous ethylene emissions initially increased, reached a peak at the intermediate stage of maturity, and finally returned to basic levels before maturing. The decrease of total respiration was observed from mitochondria which were extracted from pulp, while the involvement of AOC and UCP pathways increased significantly during papaya maturation. The amount of AOX increased during the 
transition of papaya from green to mature, accompanied by the instantaneous ethylene peak, while the $\mathrm{O}_{2}$ consumption which induced by the activity of UCP increased by $80 \%$ from the beginning to the ripening stage. The expression analysis of AOX and UCP showed that the increase of AOX and UCP (mainly UCP1) was related to the high-level expression of AOX1 and UCP, respectively. The results indicated that AOX and UCP were two different pathways related to the regulation of mature ethylene peak and the induction of specific genes such as AOX1 and UCP1.

AOX is a non-energy-saving terminal oxidase located on the electron transfer chain of plant mitochondria, while the respiratory carbon oxidation pathway, electron transfer and ATP transition are closely coupled. AOX provides a way for this coupling to relax, thus providing the metabolic balance between degree (metabolic homeostasis) to carbon and energy metabolism. In addition to its role in the initial metabolism, plant mitochondria also play a "annunciator" role which can affect such as the process of gene expression such as nucleus. The activity of AOX can control the level of potential mitochondrial signal molecules such as peroxide, NO and important redox coupling. On this path, AOX also provides a "signal balance" degree to the organelle. Metabolic and signal balance of AOX function is particularly important under stress conditions, including abiotic stresses such as hypothermia, drought, nutrient deficiency and biological stresses like bacterial infection (Vanlerberghe et al., 2013). The changes of respiratory leaps might be related to the rapid recognition of mitochondrial energy consumption system, which lead to the reduction of oxidative phosphorylation and the production of heat. The AOX pathway directly affected from the oxidation of pantothenol to the reduction of $\mathrm{O}_{2}-\mathrm{H}_{2} \mathrm{O}$, and prevented the oxidation of pantothenol through syncytic III, cytochrome $\mathrm{C}$ and cytochrome $\mathrm{C}$ oxidase (complex depression). Therefore, a branch was introduced into the mitochondrial electron transfer chain (mETC) via the electron stream of AOX, which bypassed two important energy storage points (the complex III and IV) (Figure 1) and reduced one generation of the cell membrane potential and ATP synthesis. In this way, the electron flow through the AOX path was reduced to water by parallel reaction, which increased the rate of electron transfer into mETC and heated $\mathrm{pu}$ for consumes energy. The activity of AOX also inhibited the generation of superoxide anion $\left(\mathrm{O}_{2}-\right)$, decreased its conversion to other reactive oxygen species (ROS), such as $\mathrm{H}_{2} \mathrm{O}_{2}$, hydroxyl groups and so on (Tyagi et al., 2016). The existence of two systems in the mitochondria of tomato fruit also indicated that they blocked the formation of ROS through respiratory chain and promoted fruit ripening. In the study of maturation regulation of tomato and mango, it was found that the two systems might be involved in the late maturation process (Perotti et al., 2014). The protons were pumped through the mitochondrial intima, and a proton potential was obtained from the extracellular membrane to the mesenchyma, which is driven by ATP synthase to transform into phosphorylated ADP. The role of the UCP pathway is to allow protons to provide channels from the intermembrane to the outer membrane, thus bypassing the ATP synthase complex. The UCP protein unravels ATP synthase from respiration in plant mitochondria like this. Therefore, both AOX and UCP pathway increased respiration rate (Gandin et al., 2014).



Figure 1 The plant mitochondrial electron transport chain 
Relative to the AOX path, the function of AOX pathway in energy consumption during fruit ripening is unclear. The research of Considine et al. (2001) showed that the protein accumulation of mango was related to the specific transcription of AOX (AOX1a and 1b) and UCP (UCP1) genes. Mainly occurs in mature transformation and maturation stage, and the activities of AOX and UCP significantly affected respiration. Compared with tomato, the protein level of AOX and UCP decreased in maturation stage, AOX protein level of mango and apple increased in jump stage, but UCP was not clear. This study also confirmed that AOX plays a key role in the maturation of papaya. Therefore, papaya is considered to have the characteristics of faster maturation than other jump fruits, which makes it a model to study the relationship between mitochondria uncoupling and ethylene in fruit ripening.

\subsection{Effects of polyamines on fruit ripening}

Putrescine (Put), spermidine (Spd), spermine ( $\mathrm{Spm}$ ) and other polyamines (PAs) were ubiquitous polycationic small molecules in living cells. They mainly regulated excess biological processes, such as gene expression and cell signaling and were critical to the normal growth of various organisms (Pandey et al., 2015). The PA biosynthesis pathway initiated the production of Put, and acted as the precursor of higher Pas、Spd、Spm, which was decarboxylated directly by ornithine decarboxylase (ODC). In addition to the ODC pathway, plants and bacteria also had a Put biosynthesis pathway, that is, the decarboxylation of arginine decarboxylase (ADC). Spd and Spm were synthesized from Put by adding aminopropyl groups in turn (Sauter et al., 2013).

Polyammonia (PAs) is related to fruit development and early stage of ripening, and has physiological effects such as promoting growth and relieving senescence, contrary to ethylene and so on. Contrary to ethylene effect, Valero et al. (2002) treated with PAs on many different fruits, the results showed that it could delay fruit color change, respiration and senescence, increase hardness of fruit and stability of cell wall stability, as well as reduce the damage which was caused by mechanical injury and cold injury. PAs together with salicylic acid regulated ethylene biosynthesis by affecting the accumulation of ACC synthase transcripts. PAs and ethylene acted on the contrary, by sharing $S$-Adenosyl methionine (SAM) as precursors to affect plant growth and senescence, plant cells transferred SAM into PA biosynthesis, or ethylene biosynthesis, or both (Lasanajak et al., 2014). Nambeesan et al. (2010) confirmed that lycopene content and juice viscosity increased by studying the transgenic over-expression of yeast SAMPC and yeast SPDC of tomato. These studies suggested that PA-ethylene plays an important role in fruit ripening.

\subsection{Regulatory effects of transcription factors on fruit ripening}

In recent years, with the development of genomics and molecular genetics, in fruit trees, the mining and development of functional genes related to maturation have been reported. There are nearly 60 transcription factors involved in fruit development, maturation and quality formation, such as papaya (Zhu et al., 2012), tomatoes (Exposito-Rodriguez et al., 2008; Kou et al., 2016), bananas (Chen et al., 2011), sweet oranges (Mafra et al., 2012), pears (Imai et al., 2014), and peaches (Tong et al., 2009) etc. These studies provide a good genomic data platform for the analysis of important fruit agronomic traits, as well as lay a solid foundation for the cultivation of new varieties of fruit trees. In recent years, more and more new methods and new technologies have emerged, such as Transcriptome sequencing technique, digital gene expression profiling, whole genome resequencing, epigenomics research etc., which also played an important role in promoting the development of molecular genetics of fruit trees. RNA-Seq and qRT-PCR are commonly used methods for the analysis of gene expression products during plant development. qRT-PCR is characterized by its high sensitivity, strong specificity and good compatibility and quantification range from high throughput to accurate expression products. Considered to be the most effective method for transcriptional data validation (Gonzalez-Aguero et al., 2013).

Banana's ripening process is mainly regulated by hormones such as ethylene, ABA etc. During banana maturation, ethylene, as a signaling molecule, binds to corresponding receptors and induces some physiological changes, such as the conversion of starch to sugar, the change of enzyme activity in fruit which then change the direction of enzyme activity and so on. Therefore, the ripening process of post-harvest banana is also an important process of fruit quality (hardness, aroma, color, etc.) (Giovannoni, 2004). The regulation of post-harvest quality of banana 
fruit is the key to obtain high quality banana fruit. Xu et al. (2007) used SMART PCR cDNA synthesis method to report the changes of mRNA content of natural ripe banana fruits at $28^{\circ} \mathrm{C}$ after harvest. Preliminary analysis of gene expression showed that the up-regulated gene was closely related to post-harvest ethylene biosynthesis of fruit, which suggested that it might be involved in ethylene biosynthesis or regulation of post-harvest ethylene biosynthesis in banana. Liu et al. (2015) studied the regulation of banana fruit ripening and ethylene biosynthesis, then, they speculated that MuMADS1 and MaOFP1 genes were involved in the regulation of banana ripening in an antagonistic manner. However, the interaction between fruit ripening regulators and its downstream effectors is not well understood.

\section{Fruit Quality Improvement}

\subsection{Physiological regulation mechanism of fruit quality improvement}

The fruit can be divided into two types according to the amount of ethylene produced: climacteric fruit and Non-climacteric fruit. For climacteric fruits, such as mango, banana and papaya, the content of ethylene increased rapidly with the appearance of respiratory peak at maturity. However, no significant changes in respiration were observed in non-climacteric fruits, such as grapes and strawberries, and ethylene remained at a lower level. However, this difference is not absolute, such as muskmelon fruit, which both has climacteric type and non-climacteric type. Ethylene dependent gene regulatory networks and ethylene-independent regulatory networks exist at the same time (Saladié et al., 2015). According to the results of the existing research on postharvest ethylene, in order to prolong the shelf life of fruits, climacteric fruits were generally harvested and stored in cold storage when the fruit is not fully matured. But the fruit which was not fully mature usually cannot be ripened in time, and its flavor and color would be affected (El-Sharkawy et al., 2016).

The research showed that the aroma of tomato was related to a series of complex volatile compounds. The total amount of acetate in red tomato is lower than that in green tomato, so the less the content of acetate, the more popular is (Tikunov et al., 2013). Goulet et al. (2012) reported that the difference of volatile ester content between red tomato and green tomato might be related to the insertion of a transposon, which was adjacent to a key enzyme involved in the decomposition of volatile ester of red tomato, but the green tomato lacked this insertion transposon. This insertion gradually increased the activity of the enzyme and reduced the volatile ester content of red tomato. The results of this research partly explain why many people prefer red tomatoes to green tomatoes. For many years, before maturing, growers plucked aqua fruit with uniform appearance which made it easier for people to harvest tomatoes with uniform maturity, but they were even in color compared to wild tomatoes. There is less sugar in it. Botanists discovered a transcription factor called $S l G L K 2$, which regulates the accumulation and distribution of chlorophyll. Chloroplasts use their captured light energy to convert carbon dioxide and water into sugar. However, the SlGLK2 of most tomatoes on supermarket shelves is inactivated, and the SlGLK2 expression of wild tomato is normal, which might explain why the tomato has no taste. This study also showed that some of the planting patterns which increased yields in breeding were the culprit for the decline in quality (Powell et al., 2012).

Fruit ripening is a complex process involving biochemical, metabolic and physiological changes, resulting in changes in aroma, color, taste and texture (Giovannoni, 2004). These changes are closely related to hormone regulation, cell wall modification, enzyme biosynthesis/degradation, and the changes of sugar content. This series of behaviors is arrived in a certain way by the transcriptional regulation of a set of genes associated with maturation (Prasanna et al., 2007). Pandey et al. (2015) studied the overexpression of mouse ornithine decarboxylase gene in transgenic tomato under the control of fruit extension promoter (2A11). The transgenic fruit showed that the level of diamine putrescine (Put), spermidine (Spd), spermine (Spm) increased with the decrease of ethylene level, respiration rate and physiological water loss. The results showed that the ripening period and shelf life of transgenic fruit were longer than that of non-transgenic control, and the contents of total soluble solids, titratable acid, total sugar, lycopene $\mathrm{VC}$ and antioxidants were increased in some quality characteristics. 


\subsection{Fruit texture regulation}

Fruit softening after ripening is a very complicated process. The destruction of cell wall structure is the main cause of tomato fruit softening (Duangit et al., 2016). The cell wall of tomato fruit is mainly composed of cellulose, hemicellulose, pectin and protease. Hemicellulose is a macromolecular skeleton of hemicellulose, which is composed of $\beta-1,4$ xylose unit. The hemicellulose is covalently bound to pectin and hydrogen bond to cellulose (Peneau et al., 2006). Han et al. (2008) found that the activity of polygalacturonase(PG) enzyme was strongly inhibited in transgenic fruit and played an important role in fruit softening during mature period by comparing tomato antisense PG gene with control fruit.

Although the degradation of cell wall structural substances in pulp by cell wall hydrolases is generally considered to be the main factor of fruit softening during tomato fruit ripening and storage. However, with the further study of fruit maturation, it was found that fruit softening was not only related to the degradation of cell wall, but also related to many factors, such as intracellular composition, degree of intercellular polymerization and cell pressure. Tomassen et al. (2007) found that a nonspecific lipid transfer protein (nsLTP) might be involved in the regulation of tomato fruit softening. This protein was a P subunit of PG polyprotein complex, which had the ability to catalyze the activity of PG-2a and accelerate the degradation of tomato pulp cell wall. The research of malic enzyme in tomato fruit by Centeno et al. (2010) showed that the activity of malic enzyme was closely related to the content of intermediate starch in tomato fruit and affected the post-harvest ripening softening and water loss rate. By inhibiting the activity of two glycosidases controlling the degradation of glycoprotein N-glycan in tomato fruit, Meli et al. (2010) increased the shelf life of tomato fruit by nearly 30 days. In addition, some genes related to non-hydrolytic enzymes and other metabolic pathways were also involved in the regulation of the process of fruit ripening and softening (Gapper et al., 2013). For example, the molecular morphology of starch in tomato pulp affected and involved in the physiological process of fruit ripening and softening. It was also found that the crystal structure and amylopectin ratio of starch in pulp were related to the storage ability of fruit (Kietsuda et al., 2012).

\subsection{QTL molecular marker assisted breeding for fruit quality improvement}

In order to understand the relationship and interaction between quantitative trait genes in fruit trees more deeply, quantitative trait locus (QTL) technology provides a more effective means for the mapping of multiple loci. At present, at the molecular level, many major QTL loci that control fruit traits have been mapped by researchers, such as genes that control fruit quality traits, which directly affect the appearance, flavor and quality traits related to maturity of fruits (Fu et al., 2015). Aromatic substances were one of the main components affecting fruit flavor, while they were composed of different volatile substances (Dudareva and DellaPenna, 2013). Lecomte et al. (2004) constructed the recombinant inbred line population of tomato and had located the QTL sites controlling sugar content and sweetness by QTLs. Bai et al. (2015) located the dominant QTL malic acid (Ma) on chromosome 16 to control the malic acid changes in apple natural mutants, and confirmed that Mal gene was the major gene regulating malic acid content in apple natural mutants. Molina-Bravo et al. (2014) used hybrids of (Rubus Parvifolius Tulameen) Qualicum to construct genetic linkage map to analyze the quantized characteristic transposon (QTL) of cold resistance, thorn density, fruit color, fruit shape, fruit size and flower color. Seven linkage maps were constructed and compared with the constructed Rubus map. The results showed that four regions were related to cold resistance traits and two were linked to thorn density. Saeed et al. (2014) used 250 seedlings of interspecific hybrids of pear from Asian (Pyrus pyrifolia Nakai and P.bretschneideri Rehd) and Europen (P. communis) which with two shared groups (POP369 and POP356) to identify the genetic factors of pear fruit friction discolouration(FD). The result showed that the single nucleotide polymorphism (SNP) based on linkage map was suitable for the development of two separate groups of female parents by QTL analysis. The male parent and female parent of the POP369 map contained 174 and 265 SNP markers respectively, which of POP356 map contained 353 and 398 SNP markers respectively. A total of 221 QTLs were identified as QTL associated with 22 phenotypic variations, two isolated groups and FD. The fruit hardness, polyphenol oxidase (PPO) activity, ascorbic acid (AsA) concentration, polyphenol concentration and FD related QTL were reported, 
which means FD disease was controlled by multiple small QTL effects.

Longhi et al. (2012) used Fuji apple hybrid with Delearly and Pink Lady to locate QTLs after 2 months of cold storage and evaluate the texture of the fruit. The results showed that in the Fuji apple×Delearly population, the linkage groups of more QTLs were 5, 10,15, and the interpretation rate of phenotypic variation was $15.6 / 49 \mathrm{~g}$. In the Fuji apple $\times$ Pink Lady population, the linkage groups of more QTLs were 12, 16. The main difference between these two populations were that the hot spots of QTL locus associated with fruit texture were located in the 10th (Fuji apple $\times$ Delearly) and $16^{\text {th }}$ (Fuji apple $\times$ Pink Lady) linkage groups respectively. Ravaglia et al. (2013) reported that the expression of key enzyme Gene (UFGT) in flavonoid biosynthesis was up-regulated by MYB10, MYB123 and $b H L H 3$, and inhibited by MYB111 and MYB16 during peach fruit development. Similar studies have shown that grape and apple have several $M Y B$ transcription factors involved in biosynthesis of anthocyanins from pericarp, sometimes interacting with $b H L H$ and WD40 (Jaakola, 2013). There was some scholar identified three proteins, which were FaMYB9/FaMYB11, FabHLH3 and FaTTG1, by comprehensive co-expression network analysis, yeast two-hybrid interaction and arabidopsis mutant's complementation. These three proteins were the key factors for regulating the biosynthesis of strawberry proanthocyanidins (Schaart et al., 2013). Another related transcription factor FaMYB10, was involved in the regulation of anthocyanin biosynthesis in the early and late stages of receptacle in a manner that regulates maturity (Medina-Puche et al., 2014). In conclusion, many researchers have deeply studied the molecular regulation mechanism of fruit traits. They mapped QTL to specific chromosomal segments of the linkage map to analyze the linkage relationship between genes more accurately. The results provided the basis for elucidating the molecular regulation mechanism of fruit quality traits and screening good fruit characters and new candidate genes.

\section{Expectation}

The foundation of improving quality and increasing efficiency in fruit industry is to cultivate varieties of fruit trees of good quality. Modern biotechnology has developed rapidly in recent decades, which Modern biotechnology has been developed rapidly in recent decades, including gene insertion technology, molecular marker screening, quality development related promoter mining and functional analysis, and identification of biotic and abiotic stress resistance (tolerance) genes. Therefore, mastering and utilizing the genetic principle of fruit ripening and quality regulation will show a good development prospect and advantages for the development of efficient breeding methods. At the same time, it will lay a solid foundation for the cultivation of new varieties of high-quality fruit trees.

\section{Authors' Contributions}

Tang Fenling Tang was the main writer of this review; Lin Fei, Li Yujia, Li Yanxia, Xu Yi and Huang Dongmei involved in the material arrangement, data collection and analysis of the paper; Li Jingyang was the author and responsible person in charge of the review paper. All the authors read and agree to the final text.

\section{Acknowledgement}

This research was supported by the earmarked fund for China Agriculture Research System (CARS-31-02) and Hainan Banana Healthy Seedling Propagation Engineering Research Center Fund. Agricultural Science and Technology Innovation Program of CAAS "Evaluation and Regulation of Nutritional Quality of Major Agricultural Products" (CAAS-XTCX20190025-4), Guizhou science and technology talent cooperation platform ([2019]5255).

\section{References}

Bai Y., Dougherty L., Cheng L.L., Zhong G.Y., and Xu K.Y., 2015, Uncovering co-expression gene network modules regulating fruit acidity in diverse apples, BMC Genomics https://doi.org/10.1186/s12864-015-1816-6

Centeno C.J., Schultz J.R., Cheever M., Freeman M., Robinson B., Marasco W., and Hanson R., 2010, Safety and complications reporting on the re-implantation of culture-expanded mesenchymal stem cells using autologous platelet lysate technique, Curr. Stem. Cell Res. Ther., 5(1): 81-93 https://doi.org/10.2174/157488810790442796

Chen L., Zhong H.Y., Kuang J.F., Li J.G., Lu W.J., and Chen J. Y., 2011, Validation of reference genes for RT-qPCR studies of gene expression in banana fruit under different experimental conditions, Planta, 234(2): 377-390 
https://doi.org/10.1007/s00425-011-1410-3

Chen X.S., Guo W.W., Xu J., Cong P.H., Wang L.R., Liu C.H., Li X.G., Wu S.J., Yao Y.X., and Chen X.L., 2015, Genetic improvement a nd promotion of fruit quality of main fruit trees, Zhongguo Nongye Kexue (Scientia Agricultura Sinica), 48(17): 3524-3540

Considine M.J., Daley D.O., and Whelan J., 2001, The expression of alternative oxidase and uncoupling protein during fruit ripening in mango, Plant Physiol., 126(4): 1619-1629 https://doi.org/10.1104/pp.126.4.1619

Duangjit J., Causse M., and Sauvage C., 2016, Efficiency of genomic selection for tomato fruit quality, Mol. Breeding, Doi: 10.1007/s11032-016-0453-3 https://doi.org/10.1007/s11032-016-0453-3

Dudareva N., and DellaPenna D., 2013, Plant metabolic engineering: future prospects and challenges, Curr. Opin. Biotechnol., 24(2): 226-228 https://doi.org/10.1016/j.copbio.2013.02.002

El-Sharkawy I., Sherif S., Kayal W.E.L., Jones B., Li Z., Sullivan A.J., and Jayasankar S., 2016, Overexpression of plum auxin receptor PslTIR1 in tomato alters plant growth, fruit development and fruit shelf-life characteristics, BMC Plant Biol., Doi: 10.1186/s12870-016-0746-z https://doi.org/10.1186/s12870-016-0746-z

Exposito-Rodriguez M., Borges A.A., Borges-Perez A., and Perez J., 2008, Selection of internal control genes for quantitative real-time RTPCR studies during tomato development process, BMC Plant Biol., Doi: 10.1186/1471-2229- 8-131 https://doi.org/10.1186/1471-2229-8-131

Fu W.Y., Wei Q.Z., Wang J., Wang Y.Z., Chen J.F., and Lou Q.F., 2015, Research advance in the molecular basis of fruit domestication traits in horticultural crops, Fenzi Zhiwu Yuzhong (Molecular Plant Breeding), 13(11): 2647-2654

Gandin A., Denysyuk M., and Cousins A.B., 2014, Disruption of the mitochondrial alternative oxidase (AOX) and uncoupling protein (UCP) alters rates of foliar nitrate and carbon assimilation in Arabidopsis thaliana, J. Exp. Bot., 65(12): 3133-3142 https://doi.org/10.1093/jxb/eru158

Gapper N.E., McQuinn R.P., and Giovannoni J.J., 2013, Molecular and genetic regulation of fruit ripening, Plant Mol. Biol., 82(6): $575-591$ https://doi.org/10.1007/s11103-013-0050-3

Giovannoni J.J., 2004, Genetic regulation of fruit development and ripening, Plant Cell, 16(S): 170-180

Gonzalez-Aguero M., Garcia-Rojas M., Di Genova A., Correa J., Maass A., Orellana A., and Hinrichsen P., 2013, Identification of two putative reference genes from grapevine suitable for gene expression analysis in berry and related tissues derived from RNA-Seq data, BMC Genomics https://doi.org/10.1186/1471-2164-14-878

Goulet C., Mageroy M.H., Lam N.B., Floystad A., Tieman D.M., and Klee H.J., 2012, Role of an esterase in flavor volatile variation within the tomato clade, Proc. Natl. Acad. Sci. USA., 109(46): 19009-19014 https://doi.org/10.1073/pnas.1216515109

Han X., Jiang N., Schaffner E., Stockinger E.J., and Van Der Knaap E., 2008, Aretrotransposon-mediated gene duplication underlies morphological variation of tomato fruit, Science, 319(5869): 1527-1530 https://doi.org/10.1126/science. 1153040

Imai T., Ubi B.E., Saito T., and Moriguchi T., 2014, Evaluation of reference genes for accurate normalization of gene expression for real time-quantitative PCR in Pyrus pyrifolia using different tissue samples and seasonal conditions, PLoS One, 9(1): e86492 https://doi.org/10.1371/journal.pone.0086492

Jaakola L., 2013, New insights into the regulation of anthocyanin biosynthesisin fruits, Trendsin Plant Science, 18(9): 477-483 https://doi.org/10.1016/j.tplants.2013.06.003

Kietsuda L., Saltveit M., and Beckles D.M., 201 2, Metabolite content of harvested Micro-Tom tomato (Solanum lycopersicum L.) fruit is altered by chilling and protective heat-shock treatments as shown by GC-MS metabolic profiling, Postharvest Biology and Technology, 63(1): 116-122 https://doi.org/10.1016/j.postharvbio.2011.05.014

Kou X.H., Liu C., Han L.H., Wang S., and Xue Z.H., 2016, NAC transcription factors play an important role in ethylene biosynthesis, reception and signaling of tomato fruit ripening, Mol. Genet. Genomics, 291(3): 1205-1217 https://doi.org/10.1007/s00438-016-1177-0

Lasanajak Y., Minocha R., Minocha SC., Goyal R., Fatima T., Handa AK., and Mattoo AK., 2014, Enhanced flux of substrates into polyamine biosynthesis but not ethylene in tomato fruit engineered with yeast S-adenosylmethionine decarboxylase gene, Amino Acids, 46(3): 729-742 https://doi.org/10.1007/s00726-013-1624-8

Lecomte L., Gautier A., Luciani A., Duffé P., BuretM., and Causse M., 2004, Recent advances in molecular breeding: the example of tomato breeding for flavor traits, Acta. Horticulturae, 637: 231-242 https://doi.org/10.17660/ActaHortic.2004.637.28

Liu J., Zhang J., Hu W., Miao H., Zhang J., Jia C., Wang Z., Xu B., and Jin Z., 2015, Banana Ovate family protein MaOFP1 and MADS-box protein MuMADS1 antagonistically regulated banana fruit ripening, PLoS One, 10(4): e0123870 https://doi.org/10.1371/journal.pone.0123870

Longhi S., Moretto M., Viola R., Velasco R., and Costa F., 2012, Comprehensive QTL mapping survey dissects the complex fruit texture physiology in apple (Malm domestica Borkh.), J. Exp. Bot., 63(3): 1107-1121 https://oi.org/10.1093/jxb/err326 
Mafra V., Kubo K.S., Alves-Ferreira M., Ribeiro-Alves M., Stuart RM., Boava L.P., Rodrigues C.M., and Machado M.A., 2012, Reference genes for accurate transcript normalization in citrus genotypes under different experimental conditions, PLoS One, 7(2): e31263 https://doi.org/10.1371/journal.pone.0031263

Medina-Puche L., Cumplido-Laso G., Amil-Ruiz F., Hoffmann T., Ring L., Rodríguez-Franco A., Caballero J L., Schwab W., Munoz-Blanco J., and Blanco-Portales R., 2014, MYB10 plays a major role in the regulation of flavonoid/phenylpropanoid metabolism during ripening of Fragaria $\times$ ananassa fruits, J. Exp. Bot., 65(2): 401-417 https://doi.org/10.1093/jxb/ert377

Meli V.S., Ghosh S., Prabha T.N., Chakraborty N., Chakraborty S., and Datta A., 2010, Enhancement of fruit shelf life by suppressing N-glycan processing enzymes, Proc. Natl. Acad. Sci. USA, 107(6): 2413-2418 https://doi.org/10.1073/pnas.0909329107

Molina-Bravo R., Fernandez G.E., and Sosinski B.R., 2014, Quantitative trait locus analysis of tolerance to temperature fluctuations in winter, fruit characteristics, flower color, and prickle-free canes inraspberry, Mol. Breeding, 33(2): 267-280 https://doi.org/10.1007/s11032-013-9947-4

Nambeesan S., Datsenka T., Ferruzzi M.G., Malladi A., Mattoo A.K., and Handa A.K., 2010, Overexpression of yeast spermidine synthase impacts ripening, senescence and decay symptoms in tomato, Plant J., 63(5): 836-847 https://doi.org/10.1111/i.1365-313X.2010.04286.x

Oliveira M.G., Mazorra L M., Souza A.F., Silva S.F., Correa S.F., Santos W.C., Saraiva A.J., Teixeira A.J.J., Melo D.F., Silva M.A., Arra bac J.D., Costa J.H., and Oliveira J.G., 2015, Involvement of AOX and UCP pathways in the post-harvest ripening of papaya fruits, J. Plant Physiol., 189: 42-50 https://doi.org/10.1016/j.jplph.2015.10.001

Pandey R., Gupta A., Chowdhary A., Pal R.K., and Rajam M.V., 2015, Over-expression of mouse ornithine decarboxylase gene under the control of fruit specific promoter enhances fruit quality in tomato, Plant Mol. Biol., (87): 249-260 https://doi.org/10.1007/s11103-014-0273-y

Peneau S., Hoehn E., Roth H.R., Escher F., and Nuessli J., 2006, Importance and consumer perception of freshness of apples, Food Quality and Preference, 17(1-2): 9-19 https://doi.org/10.1016/i.foodqual.2005.05.002

Perotti V.E., Moreno A.S., and Podestá F.E., 2014, Physiological aspects of fruit ripening: the mitochondrial connection, Mitochondrion, 17: $1-6$ https://doi.org/10.1016/i.mito.2014.04.010

Powell A.L., Nguyen C.V., Hill T., Cheng K.L., Figueroa-Balderas R., Aktas H., Ashrafi H., Pons C., Fernández-Muñoz R., Vicente A., Lopez-Baltazar J., Barry C.S., Liu Y., Chetelat R., Granell A., Van Deynze A., Giovannoni J.J., and Bennett A.B.,2012, Uniform ripening encodes a golden 2-like Transcription factor regulating tomato fruit chloroplast development,Science, 336(6089): 1711-1715 https://doi.org/10.1126/science. 1222218

Prasanna V., Prabha T.N., and Tharanathan R.N., 2007, Fruit ripening phenomena-an overview, Crit. Rev. Food Sci. Nutr., 47(1): 1-19 https://doi.org/10.1080/10408390600976841

Ravaglia D., Espley R.V., Henry-Kirk R.A., Andreotti C., Ziosi V., Hellens R.P., Costa G., and Allan A.C., 2013, Transcriptional regulation of flavonoid biosynthesis in nectarine (Prunus persica) by a set of R2R3 MYB transcription factors, BMC Plant Biol., DOI: 10.1186/1471-2229-13-68 https://doi.org/10.1186/1471-2229-13-68

Saeed M., Brewer L., Johnston J., McGhie K.T., Gardiner S.E., Heyes J.A., and Chagné D., 2014, Genetic, metabolite and developmental determinism of fruit friction discolouration in pear, BMC Plant Biol., Doi: 10.1186/s12870-014-0241-3 https://doi.org/10.1186/s12870-014-0241-3

Saladié M., Cañizares J., Phillips M.A., Rodriguez-Concepcion M., Larrigaudière C., Gibon Y., Stitt M., John E.L., and Garcia-Mas J., 2015, Comparative transcriptional profiling analysis of developingmelon (Cucumis meloL.) fruit from climacteric and non-climacteric varieties, BMC Genomics https://doi.org/10.1186/s12864-015-1649-3

Sauter M., Moffatt B., Saechao M.C., Hell R., and Wirtz M., 2013, Methionine salvage and S-adenosylmethionine: essential links between sulfur, ethylene and polyamine biosyn thesis, Biochem J., 451(2): 145-154 https://doi.org/10.1042/BJ20121744

Schaart J.G., Dubos C., Romero De La Fuente I., van HouwelingenA.M., De Vos R.C., Jonker H.H., Xu W., Routaboul J.M., Lepiniec L., and Bovy A.G., 2013, Identification and characterization of MYB-bHLH-WD40 regulatory complexes controlling proanthocyanidin biosynthesis in strawberry (Fragaria $\times$ ananassa) fruits, New Phytol., 197(2): 454-467 https://doi.org/10.1111/nph.12017

Seymour G.B., Ostergaard L., Chapman N.H., Knapp S., and Martin C., 2013, Fruit development and ripening, Ann. Rev. Plant Biol., 64: $219-241$ https://doi.org/10.1146/annurev-arplant-050312-120057

Tikunov Y.M., Molthoff J., De Vos R.C., Beekwilder J., Van Houwelingen A., Van Der Hooft J.J., Nijenhuis-de Vries M., Labrie C.W., Verkerke W., Van De Geest H., Viquez Zamora M., Presa S., Rambla J.L., Granell A., Hall R.D., and Bovy A.G., 2013, Non-smoky glycosyltransferase1 prevents the release of smoky aroma from tomato fruit, The Plant Cell, 25(8): 3067-3078

https://doi.org/10.1105/tpc.113.114231

Tomassen M.M., Barren D.M., Van Der Valk H.C., and Woltering E.J., 2007, Isolation and characterization of a tomato non-specific lipid transfer protein 
Molecular Plant Breeding 2019, Vol.10, No.14, 108-115

http://genbreedpublisher.com/index.php/mpb

involved in polygalacturon-ase-mediated pectin degradation, J. Exp. Bot., 58(5): 1151-1160

https://doi.org/10.1093/jxb/erl288

Tong Z., Gao Z., Wang F., Zhou J., and Zhang Z., 2009, Selection of reliable reference genes for gene expression studies in peach using real-time PCR, BMC Mol. Biol., Doi: 10.1186/1471-2199-10-71

https://doi.org/10.1186/1471-2199-10-71

Tyagi V.K, Irfan M., Ghosh S., Chakraborty N., Chakraborty S., and Datta A., 2016, Fruit ripening mutants reveal cell metabolism and redox state during ripening, Protoplasma, 253(2): 581-594

https://doi.org/10.1007/s00709-015-0836-z

Valero D., Martínez-Romero D., and Serrano M., 2002, The role of polyamines in the improvement of the shelf life of fruit, Trends Food Sci. Technol., 13(6-7): 228-234

https://doi.org/10.1016/S0924-2244(02)00134-6

Vanlerberghe G.C., 2013, Alternative oxidase: a mitochondrial respiratory pathway to maintain metabolic and signaling homeostasis during abiotic and biotic stress in plants, Int. J. Mol. Sci., 14(4): 6805-6847 https://doi.org/10.3390/ijms14046805

Xu B.Y., Su W., Liu J.H., Wang J.B., and Jin Z.G., 2007, Differentially expressed cDNAs at the early stage of banana ripening identified by suppression subtractive hybridization and cDNA microarray, Planta, 226(2): 529-539 https://doi.org/10.1007/s00425-007-0502-6

Zhu X.Y., Li X.P., Chen W.X., Chen J.Y., Lu W.L., Chen L., and Fu D.W., 2012, Evaluation of new reference genes in papaya for accurate transcript normalization under different experimental conditions, PLoS One, 7(8): e44405 https://doi.org/10.1371/journal.pone.0044405 